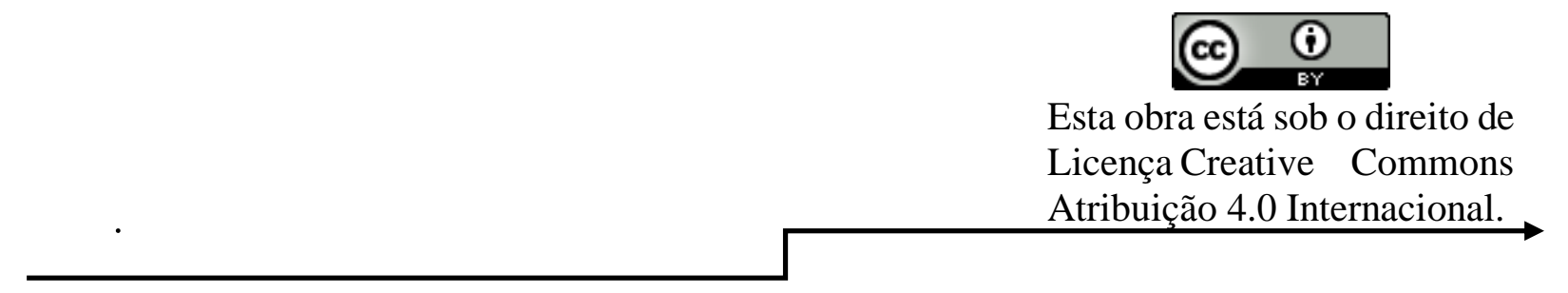

\title{
EDUCAÇÃO AMBIENTAL E SUA IMPORTÂNCIA
}

\author{
Bernard Pereira Almeidal \\ Rosineide Maria Rocha Tavares ${ }^{2}$
}

\section{RESUMO}

A degradação do meio ambiente, atualmente, se mostra constante e pode ser observada em todo o mundo. Embora a natureza seja essencial à sobrevivência humana, a preocupação com sua preservação tem sido colocada de lado. Porém, a destruição do meio ambiente coloca em risco o futuro dos próprios seres humanos e, tomando conhecimento disso, ensinos voltados à conscientização a respeito dessa questão tornam-se cada vez mais importantes. Pensando nisso, o presente estudo teve como objetivo apresentar uma análise sobre a importância do ensino da educação ambiental nas escolas como uma maneira de formar pessoas que, na sociedade, atuem de forma crítica e consciente em relação aos diversos problemas ambientais, lutando por alcançar a preservação do meio ambiente. Essa análise se deu referente aos anos iniciais do Ensino Fundamental, período em que a criança inicia seu desenvolvimento motor, cognitivo e social. Para tal, partiu de uma revisão bibliográfica como metodologia de pesquisa, por meio da qual pode coletar dados necessários à elaboração do estudo com um levantamento de fontes teóricas. Assim, pode concluir que o ensino da educação ambiental nos anos iniciais do Ensino Fundamental é essencial para futuramente amenizar os impactos decorrentes da degradação ambiental, pois leva aos indivíduos, ainda na sua infância, informação, conhecimento e mudança de comportamento, permitindo-lhes, ainda, adquirir maior responsabilidade ambiental, ética e social.

Palavras-chave: Educação ambiental. Meio ambiente. Ensino. Anos iniciais.

\footnotetext{
${ }^{1}$ bernardadv@hotmail.com

2 Rosineidetavares0209@gmail.com
} 


\section{INTRODUÇÃO}

No Brasil, a educação ambiental é tratada pela Lei $\mathrm{n}^{\circ} 9.795$, de 27 de abril de 1999, por meio da qual foi instituída a Política Nacional de Educação Ambiental. Segundo a lei (BRASIL, 1999), a educação ambiental tem parte na educação nacional, permitindo ao indivíduo construir valores sociais e demais competências que se voltem para a conservação do meio ambiente. Nesse contexto, é um ensino que, como exposto no art. $2^{\circ}$ da Lei $n^{\circ} 9.795 / 99$, deve estar presente em todas as modalidades do processo educativo.

Com o intuito de conscientizar as pessoas quanto à má utilização dos recursos naturais e possíveis problemas consequentes da degradação do meio ambiente, que colocam em risco o próprio futuro dos seres humanos, esse ensino tem se mostrado cada vez mais importante, evoluindo como uma necessidade de se repensar a relação homem/natureza sob outra ética (ANZILIERO, 2014).

Mas, como a educação ambiental pode cooperar para a conscientização dos seres humanos em relação aos problemas ambientais, principalmente num momento em que em todo o mundo cresce o número de "ataques" ao meio ambiente? Pensando nessa questão, o presente estudo tem como objetivo apresentar uma análise sobre a importância do ensino da educação ambiental nas escolas como uma maneira de formar pessoas críticas e conscientes dos diversos problemas ambientais e da necessidade de preservação do meio ambiente.

Espera-se com esse estudo responder questões voltadas às possíveis consequências da degradação do meio ambiente aos seres humanos, à forma como a educação ambiental contribui para formar cidadãos conscientizados no que diz respeito a preservação desse ambiente, e como esse ensino pode ser aplicado nas escolas brasileiras de forma que, desde a infância, seja enraizado nas pessoas esse entendimento.

Essa pesquisa se justifica pelo anseio em colaborar para que esse cenário hoje visto, de destruição do meio ambiente, seja alterado através da conscientização. É esperado que, ao apontar os benefícios da inclusão da educação ambiental como ensino nas escolas brasileiras, possa-se formar futuros cidadãos preocupados em manter preservado um patrimônio responsável por garantir a sobrevivência dos seres vivos.

Logo, para alcançar os resultados pretendidos com o estudo, é aplicada uma metodologia de revisão bibliográfica. Esta, consiste em um levantamento de fontes teóricas, tendo como objetivo formular a contextualização da pesquisa, bem como 
seu embasamento teórico (PRODANOV;

FREITAS, 2013).

\section{A importância da educação ambiental}

Atualmente, o desrespeito ao meio ambiente tem alcançado níveis nunca vistos. Helen Briggs (2020), em reportagem da BBC News Brasil, chama atenção para o fato de que a destruição da natureza pelo homem cresce em ritmo catastrófico. Desde o ano de 1970, segundo dados apresentados pela jornalista, pode ser observada uma queda de cerca de $68 \%$ em 20 mil populações das mais diversas espécies de animais, entre pássaros, mamíferos, anfíbios, peixes e répteis, em consequência do estrago causado à natureza pela atividade humana.

Conforme expõe Alves (2016), o desmatamento de florestas, a poluição dos rios e mares, a liberação de gases poluentes na atmosfera, estão entre as principais e mais comuns atividades humanas que levam o meio ambiente ao seu desgaste. E embora a Lei $\mathrm{n}^{\circ}$ 9.795/99, que trata a questão da educação ambiental, vise a redução de tamanha destruição e a preservação do meio ambiente, esse é um ato que não tem sido facilmente alcançado.

Ao tratar essa questão, a Lei estabelece:

Art. $1^{\circ}$ Entendem-se por Educação Ambiental os processos por meio

\begin{abstract}
dos quais o indivíduo e a coletividade constroem valores sociais, conhecimentos, habilidades, atitudes e competências voltadas para a conservação do meio ambiente, bem de uso comum do povo, essencial à sadia qualidade de vida e sua sustentabilidade. (BRASIL, 1999).
\end{abstract}

Apesar de sua grande importância, a educação ambiental ainda é desconhecida por muitos cidadãos, comunidades e sociedades civis, até mesmo por operadores do Direito, como apontam Thomas et al. (2017). Isso se dá, principalmente, pela ausência de seu ensino nas escolas públicas e privadas do país, seja no ensino fundamental ou ensino médio.

O ensino da educação ambiental tem como objetivos fundamentais:

Art. $5^{\circ}$ : I - o desenvolvimento de uma compreensão integrada do meio ambiente em suas múltiplas e complexas relações, envolvendo aspectos ecológicos, psicológicos, legais, políticos, sociais, econômicos, científicos, culturais e éticos;

II - a garantia de democratização das informações ambientais; III - o estímulo e o fortalecimento de uma consciência crítica sobre a problemática ambiental e social;

IV - o incentivo à participação individual e coletiva, permanente e responsável, na preservação do equilíbrio do meio ambiente, entendendo-se a defesa da qualidade ambiental como um valor inseparável do exercício da cidadania;

$\mathrm{V}$ - o estímulo à cooperação entre as diversas regiões do País, em níveis micro e macrorregionais, 
com vistas à construção de uma sociedade ambientalmente equilibrada, fundada nos princípios da liberdade, igualdade, solidariedade, democracia, justiça social, responsabilidade e sustentabilidade;

VI - o fomento e o fortalecimento da integração com a ciência e a tecnologia;

VII - o fortalecimento da cidadania, autodeterminação dos povos e solidariedade como fundamentos para o futuro da humanidade. (BRASIL, 1999)

Entende-se, assim, que a educação ambiental consiste em um ramo da educação que tem o objetivo de disseminar conhecimentos sobre o meio ambiente para, então, cooperar com a preservação e conservação do meio ambiente, e, até mesmo, quanto à possibilidade da utilização sustentável dos recursos da natureza para evitar maior destruição desta.

\section{O meio ambiente e sua relevância para a sobrevivência humana}

Guerras e conflitos, bem como as muitas evoluções tecnológicas, não provocam mudanças apenas na sociedade, $o$ meio ambiente é constantemente prejudicado por conta destes. Frente a essas questões, tornou-se cada vez mais nítida a necessidade de se preservar um ambiente que vem sendo constantemente destruído (THOMAS, et al., 2017).

Dessa forma, Conferências, Declarações, Recomendações e Leis passaram a ser estabelecidas na busca pela preservação da natureza. Segundo Thomas et al. (2017), ainda no ano de 1972, foi realizada a Conferência de Estocolmo, a primeira da história para debater as questões atinentes ao meio ambiente. Esta contou com a participação de unidades e agências especializadas da Organização das Nações Unidas (ONU), 113 Estados e 250 organizações não governamentais (ONGs).

Desta Conferência foi aprovada a Declaração sobre o Meio Ambiente Humano, também conhecida como Declaração de Estocolmo, que é considerada um marco histórico para a Educação Ambiental, pois, de acordo com Pedrini (2000), tornou-se um instrumento essencial na solução da crise ambiental internacional. Tal Declaração contou com a participação e aprovação do Brasil.

A partir da Conferência de Estocolmo foi produzido também o Plano de Ação para o Meio Ambiente Humano, por meio do qual foram estabelecidas 109 recomendações para tratar as medidas internacionais para apoiar as ações de avaliação e de gestão, as atividades de gestão ambiental e o programa global de avaliação ambiental (PEDRINI, 2000).

Atualmente, o apoio ao meio ambiente tem sua importância cada vez mais perceptível. Isso se dá, segundo Santos, Reis e Tavares (2012), porque: 
O planeta vivencia um período de constantes transformações no que se refere ao meio ambiente [...]. Toda a mídia expõe suas atenções para a ação dos seres humanos com a natureza, frente aos incêndios florestais, ao desmatamento, sobre a desigualdade social, dos bens produzidos, da justiça social, de igualdade, do direito e da alimentação, dentre outros. A paisagem natural historicamente vem se modificando com as intervenções dos seres humanos, deixando de ser uma paisagem natural e passando a ser uma paisagem transformada... (SANTOS; REIS; TAVARES, 2012, p. 133).

Dessa forma, a Educação Ambiental começou a ser apresentada como uma necessidade e direito do homem a um desenvolvimento ecologicamente equilibrado, além de um instrumento indispensável à vida humana com dignidade, fosse às gerações da época ou às gerações futuras, a partir da compreensão de que apenas por intermédio da educação o ser humano seria capaz de se conscientizar quanto ao meio ambiente e questões ambientais (PIOVESAN, 2015).

Atualmente, é cada vez mais nítido que os riscos ambientais estão diretamente relacionados com o comportamento humano. Em grande parte, tratam-se dos imprevisíveis efeitos da globalização. O fato é que o progresso gerado pelo constante desenvolvimento tanto das ciências quanto da tecnologia tem se mostrado, segundo Arana e Klebis (2013), como uma fonte potencial de autodestruição da sociedade industrial. Ainda, a partir destas, novos riscos de caráter global são produzidos, o que não apenas afeta o planeta e seu meio ambiente, mas também atravessa fronteiras nacionais e de classes sociais.

Logo, considerando que as questões ambientais estão cada vez mais presentes no cotidiano da sociedade, apresentando-se como uma questão que precisa ser trabalhada com todas as pessoas que fazem parte dessa sociedade (MEDEIROS, et al., 2011), a aplicação da educação ambiental como um ensino nas escolas brasileiras pode muito auxiliar para que, futuramente, cidadãos mais críticos e conscientes sobre essas questões tomem parte no enfrentamento dos problemas ambientais.

\section{A educação ambiental nos anos iniciais do ensino fundamental}

Os anos iniciais do Ensino Fundamental no Brasil, constituído do $1^{\circ}$ ao $5^{\circ}$ ano, envolvem a alfabetização e o desenvolvimento motor, cognitivo e social das crianças, por meio, principalmente, de atividades lúdicas, ou seja, jogos e brincadeiras que auxiliam um ensino prático. Dessa forma, a criança aprende não pela teoria, mas pela ação, executando movimentos que lhe divirtam, movimentos recreativos (ARRIADA, et al., 2013).

Segundo Marques (2017), as atividades lúdicas têm promovido uma 
melhor e mais impactante aprendizagem nas crianças durante os anos iniciais do Ensino Fundamental. Por meio destas elas podem explorar mais sua criatividade e fortalecer seu lado emocional, bem como sua conduta no processo de ensinoaprendizagem. Isso ocorre porque, sendo, essas atividades, uma ferramenta pedagógica com a capacidade de despertar a imaginação da criança de forma significativa, em muito contribuem para o desenvolvimento cognitivo que estimula as relações interpessoais.

Segundo Brougère (2008, apud ARRIADA, et al., 2013, p. 75-76):

Essa cultura lúdica não está fechada em torno de si mesma, ela integra elementos externos que influenciam a brincadeira: atitudes e capacidades, cultura e meio social. Os brinquedos se inserem nesse contexto. [...] novas estruturas de brincadeiras, ou desenvolvimento de algumas em detrimento de outras, novas representações: o brinquedo contribui para o desenvolvimento da cultura lúdica. (BROUGÈRE, 2008, apud ARRIADA, et al., p. 75-76).

Com a utilização de jogos, brincadeiras diversas e brinquedos, é permitido à criança alcançar uma representação de ambientes e objetos externos em sua aprendizagem, ampliando sua imaginação e, assim, seu conhecimento (ARRIADA, et al., 2013).
A partir desse entendimento, podese considerar que um novo ensinamento, quando aplicado às crianças dos anos iniciais por meio de atividades lúdicas, pode ter maior efeito nessas crianças do que em crianças mais velhas ou, até mesmo, em pessoas adultas. Isso pode levar ao consenso de que o ensino da educação ambiental nos anos iniciais do Ensino Fundamental pode causar maior comoção do que o mesmo ensino nos anos finais do Ensino Fundamental, Ensino médio ou Ensino Superior.

Segundo Medeiros et al. (2011, p. 2), “a educação ambiental é um processo pelo qual o educando começa a obter conhecimentos acerca das questões ambientais". Nessa etapa, é inserida no estudante uma nova visão sobre o meio ambiente, na busca por tornar clara a necessidade da preservação e conservação do meio ambiente.

Badr (2011, apud THOMAS, et al., 2017, p. 22) coloca o ensino como uma "transmissão de conhecimentos, de informações ou esclarecimentos úteis ou indispensáveis à educação". Quanto à educação, trata-se do nome dado ao processo de ensino que prepara um indivíduo para o exercício da cidadania, habilitando-o para o trabalho e a convivência social. Essa educação é formada a partir da transmissão de um conjunto de conhecimentos necessários, de 
forma que possa contribuir efetivamente com o desenvolvimento pleno de uma pessoa.

Dessa forma, tomar a educação ambiental como um ensino é coloca-la como essencial, indispensável, útil à sociedade, útil à formação e desenvolvimento de cada pessoa, de forma que possa melhor contribuir para com o meio ambiente.

\section{O ensino da educação ambiental nas escolas brasileiras}

Santos, Reis e Tavares (2012) apontam que, sendo uma instituição responsável pela formação dos cidadãos, a escola tem o dever social de desenvolver um sistema de conhecimentos, habilidades e valores que sustentem um comportamento racional também sobre o meio ambiente, pois ele está presente na vida de todas as pessoas, queiram elas ou não. Para os autores, praticar a educação ambiental é essencial para a compreensão dos dilemas existentes atualmente em relação às questões ambientais.

Nesse contexto, deve haver uma interligação entre a Educação Escolar e a Educação Ambiental. Além do ensino já passado nas escolas, de acordo com Medeiros et al. (2011), os professores devem empenhar-se também na busca da melhoria do planeta e por melhores condições ambientais por meio da Educação Ambiental.

Considerando que as questões ambientais estão cada vez mais presentes na sociedade e precisam ser trabalhadas no meio desta, entende-se que uma das melhores formas de se as trabalhar é nas escolas, onde, ainda quando crianças, as pessoas são educadas e ensinadas sobre diversos temas de relevância à sociedade (MEDEIROS, et al., 2011).

\begin{abstract}
A educação ambiental nas escolas contribui para a formação de cidadãos conscientes, aptos para decidirem e atuarem na realidade socioambiental de um modo comprometido com a vida, com o bem-estar de cada um e da sociedade. Para isso, é importante que, mais do que informações e conceitos, a escola se disponha a trabalhar com atitudes, com formação de valores e com mais ações práticas do que teóricas para que o aluno possa aprender a amar, respeitar e praticar ações voltadas à conservação ambiental. (MEDEIROS, et al., 2011, p. 2-3)
\end{abstract}

Tornando-se nítida a importância desse ensinamento nas escolas brasileiras, novas propostas educativas, bem como novas visões de mundo, têm surgido na inserção da educação ambiental em escolas de Ensino Fundamental no Brasil (SOUSA, 2018). Uma pesquisa do Instituto Nacional de Estudos e Pesquisas Educacionais Anísio Teixeira (INEP), ainda no ano de 2004, já apontava um aumento no ensino da educação ambiental nessas escolas. 
A pesquisa do INEP demonstrou que, em 2004, o Estado do Amazonas possuía um índice de $92,5 \%$ de escolas de Ensino Fundamental que incluíram a educação ambiental em seus currículos. No Centro-Oeste, 73,2\% dos estabelecimentos de ensino já haviam adotado essa política. $\mathrm{O}$ Estado de São Paulo contava com 65,9\% de escolas com programas e projetos específicos sobre o meio ambiente. A Região Sul do país tinha 50,6\% de escolas que praticavam o ensino da educação ambiental (INEP, 2004).

Atualmente, essas taxas se mostram reduzidas. Porém, a importância da implementação da educação ambiental nas escolas torna-se cada vez maior, principalmente por ter aumentado

\section{METODOLOGIA}

Trata-se de uma revisão de literatura tradicional, não sistemática, descritiva, de

\section{CONCLUSÃO}

Com o intuito de trazer uma análise a respeito da importância do ensino da educação ambiental nas escolas brasileiras na luta por formar cidadãos críticos e conscientes sobre os muitos problemas ambientais, bem como a necessidade de preservação do meio ambiente, o estudo se dedicou a apresentar o conceito de Educação Ambiental, segundo a Lei ${ }^{\circ}$ 9.795/99, sua importância para a sociedade consideravelmente o número de habitantes no planeta, chegando a cerca de 7,5 bilhões de pessoas.

Vieira (2020) aponta que essa implementação pode ser feita de forma simples e básica. Além da prática de jogos e brincadeiras com o tema "meio ambiente", incentivar o consumo consciente de água e energia nas salas de aula, banheiros e bebedouros da escola, ensinar a importância das lixeiras recicláveis e fazer uma horta coletiva pode provocar grandes efeitos na aprendizagem das crianças, tornando-as futuramente, cidadãos conscientes da necessidade de preservação e conservação do meio ambiente.

natureza qualitativa, com análise de conteúdo de livros e documentos adquiridos em bibliotecas físicas e virtuais.

e sua aplicação como um ensino nos anos iniciais do Ensino Fundamental.

Por meio desse estudo pode ser observado que a educação ambiental tem sua importância reconhecida em diversos documentos, sejam nacionais ou internacionais. No entanto, a degradação ao meio ambiente, atualmente, se mostra mais forte do que já se mostrou antes. O fato é que Conferências e Declarações a respeito da preservação do meio ambiente sem a conscientização dos seres humanos não 
garante a conservação da natureza, pois os avanços tecnológicos e científicos têm sido colocados em primeiro lugar.

Nesse contexto, percebe-se que essa conscientização só pode ser alcançada através da educação, pois a educação é o que forma o cidadão. Dessa forma, pode-se entender que o surgimento e desenvolvimento da Educação Ambiental como método de ensino está diretamente relacionado ao movimento ambientalista, pois é fruto da sensibilização sobre a problemática ambiental.

De fato, a educação ambiental vem de uma necessidade de reparação sobre o meio ambiente. Essa educação nos traz uma nova forma de ler a realidade e de como atuar sobre ela. Ela pode mudar hábitos, transformar a situação do planeta terra e ainda proporcionar uma melhor qualidade de vida para as pessoas. Porém, essa deve ser ensinada e praticada.

Assim, considerando serem os anos iniciais do Ensino Fundamental, normalmente, o período em que a criança melhor se desenvolve cognitivamente, bem como em suas ações, a aplicação do ensino da educação ambiental nessa etapa pode alcançar grandes impactos e moldar a forma como essas crianças veem o meio ambiente, enxergando a necessidade da proteção deste até mesmo para a sobrevivência humana.

Nessa etapa é comum que as crianças aprendam por meio das atividades lúdicas, que são os jogos e brincadeiras, tendo em vista que, essas, melhor desenvolvem sua imaginação e criatividade.

A aplicação de atividades lúdicas para a aprendizagem das crianças nos anos iniciais do Ensino Fundamental permite uma participação prática destas com o ensinamento que lhes é passado. Nesse sentido, o ensino da educação ambiental nessa etapa pode colocar a criança em contato com a natureza ainda nos primeiros anos de sua vida, com maiores chances de despertar, nesta, a conscientização buscada pela educação ambiental, ou seja, a necessidade da preservação do meio ambiente.

Pode concluir-se, então, que o ensino da educação ambiental nos anos iniciais do Ensino Fundamental é essencial para futuramente amenizar os impactos decorrentes da degradação ambiental, pois leva aos indivíduos, ainda na sua infância, informação, conhecimento e mudança de comportamento, permitindo-lhes, ainda, adquirir maior responsabilidade ambiental, ética e social. 


\section{REFERÊNCIAS}

ALVES, L. Impactos ambientais. In: CESMAC. Meio ambiente: caderno 3. Capítulo 1, p. 1-5, Centro Universitário CESMAC, Alagoas, 2016.

ANZILIERO, D. M. A importância da preservação de áreas naturais para a biodiversidade e sustentabilidade ambiental. 2014. 40 f. Monografia de Especialização (Especialização em Educação Ambiental). Universidade Federal de Santa Maria, Santa Maria - RS, 2014.

ARANA, A. R. A.; KLEBIS, A. B. S. O. A importância da educação ambiental no contexto escolar: um estudo em presidente Epitácio-SP. Curitiba: EDUCERE, 2013.

ARRIADA, A. B.; FIORAVANTE, A. P.; ALVES, A. M.; MICHEL, C. B.; VALÉRIO, C. S.; BEHREND, D. M.; et al. Práticas pedagógicas na Educação Infantil e nos anos iniciais do Ensino Fundamental: diferentes perspectivas. Rio Grande: Universidade Federal do Rio Grande (FURG), 2013.

BRASIL (1999). Lei n ${ }^{\circ}$ 9.795, de 27 de abril de 1999. Disponível em: <http://www.planalto.gov.br/ccivil_03/leis/ 19795.htm>. Acesso em: 20 jan. 2021.

BRIGGS, H. (2020). Destruição da natureza pelo homem tem ritmo 'catastrófico': a dura advertência de cientistas. BBC News Brasil. Disponível em: <https://noticias.uol.com.br/meioambiente/ultimasnoticias/bbc/2020/09/10/destruicao-danatureza-pelo-homem-tem-ritmocatastrofico.htm>. Acesso em: 20 jan. 2021.

INEP (2004). Aumenta o número de escolas com educação ambiental.

Disponível em:

$<$ http://portal.inep.gov.br/artigo//asset_publisher/B4AQV9zFY7Bv/content /aumenta-numero-de-escolas-comeducacao-ambiental/21206>. Acesso em: 10 fev. 2021.

MARQUES, J. F. A importância das atividades lúdicas para $o$ desenvolvimento infantil. 2017. $26 \mathrm{f}$. Monografia (Graduação em Pedagogia). Universidade Federal de Juiz de Fora, Juiz de Fora, 2017.

MEDEIROS, A. B.; MENDONÇA, M. J.; SOUSA, G. L.; OLIVEIRA, I. P. A importância da educação ambiental na escola nas séries iniciais. Revista Faculdade Montes Belos, v. 4, n. 1, p.117, set. 2011.

PEDRINI, A. G. Trajetórias da Educação Ambiental. In: PEDRINI, Alexandre de Gusmão (org.). Educação Ambiental: reflexões e práticas contemporâneas. Petrópolis: Vozes, 2000. p. 21-87.

PIOVESAN, F. Direitos Humanos e o Direito Constitucional Internacional. 15 ed. - São Paulo: Saraiva, 2015.

PRODANOV, C. C.; FREITAS, E.C. Metodologia do trabalho científico: métodos e técnicas da pesquisa e do trabalho acadêmico. $-2^{\circ}$ ed. - Novo Hamburgo: Feevale, 2013.

SANTOS, F. A. S.; REIS, S. R.; TAVARES, J. A. V. Educação ambiental e sua importância para a sociedade em risco: reflexão no ensino formal. Educação e Comunicação, Edição Internacional, p. 133-146, 2012.

SOUSA, P. C. O. Educação ambiental nas escolas: uma revisão de literatura. 2018. 30 f. Trabalho de Conclusão de Curso (Licenciatura em Ciências Biológicas). - Faculdade Araguaia, Goiânia, 2018.

THOMAS, Carla; et al. Educação ambiental: conceitos, histórico, 
concepções e comentários à Lei da Política Nacional de Educação Ambiental (Lei n ${ }^{\circ}$ 9.795/99). Organizador: Eid Badr.

Programa de Pós-Graduação em Direito Ambiental da UEA (Mestrado em Direito), Editora Valer, Universidade do Estado do Amazonas, Manaus, 2017.
VIEIRA, Luiza Padovam (2020).

Educação ambiental nas escolas: por que ela deve ser implementada? Disponível em:

$<$ https://querobolsa.com.br/revista/educaca o-ambiental-nas-escolas-por-que-ela-deveser-implementada>. Acesso em: 9 fev. 2021. 